\title{
Intravitreal low molecular weight heparin and 5-Fluorouracil for the prevention of proliferative vitreoretinopathy following retinal reattachment surgery (Review)
}

\author{
Sundaram V, Barsam A, Virgili G
}

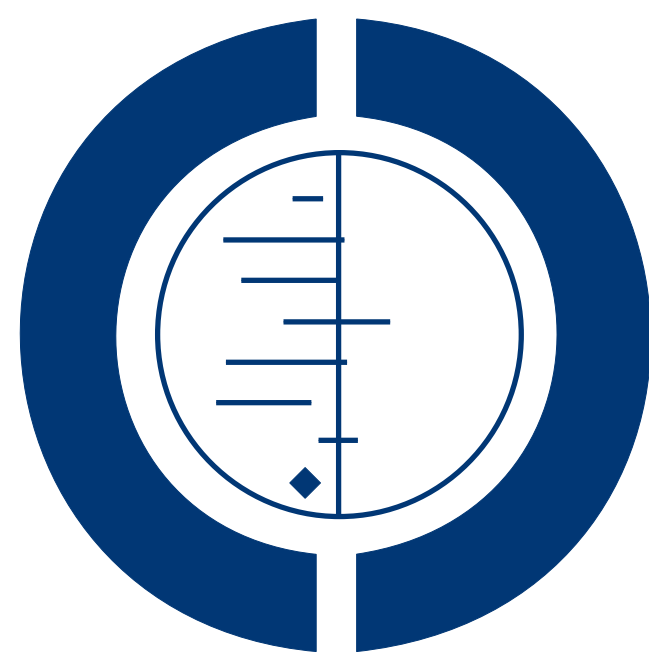

THE COCHRANE
COLLABORATION $^{\circledR}$

This is a reprint of a Cochrane review, prepared and maintained by The Cochrane Collaboration and published in The Cochrane Library 2010, Issue 7

http://www.thecochranelibrary.com

\section{WILEY}

Intravitreal low molecular weight heparin and 5-Fluorouracil for the prevention of proliferative vitreoretinopathy following retinal reattachment surgery (Review)

Copyright $\odot 2010$ The Cochrane Collaboration. Published by John Wiley \& Sons, Ltd. 
TABLE OF CONTENTS

HEADER . . . . . . . . . . . . . . . . . . . . . . . . . . . . . . . . . . . . . . . 1

ABSTRACT . . . . . . . . . . . . . . . . . . . . . . . . . . . . . . . . . . . . . . . . . . . .

PLAIN LANGUAGE SUMMARY . . . . . . . . . . . . . . . . . . . . . . . . . . . . . . . . . . 2

BACKGROUND . . . . . . . . . . . . . . . . . . . . . . . . . . . . . . . . . . . . . .

OBJECTIVES . . . . . . . . . . . . . . . . . . . . . . . . . . . . . . . . . . . . . .

METHODS . . . . . . . . . . . . . . . . . . . . . . . . . . . . . . . . . . . . . .

RESULTS . . . . . . . . . . . . . . . . . . . . . . . . . . . . . . . . . . . . . 5

Figure 1. . . . . . . . . . . . . . . . . . . . . . . . . . . . . . . . . . . . 6

DISCUSSION . . . . . . . . . . . . . . . . . . . . . . . . . . . . . . . . . . . . . . .

AUTHORS' CONCLUSIONS . . . . . . . . . . . . . . . . . . . . . . . . . . . . . . . . . . . . . . .

ACKNOWLEDGEMENTS . . . . . . . . . . . . . . . . . . . . . . . . . . . . . . . . . . . .

REFERENCES . . . . . . . . . . . . . . . . . . . . . . . . . . . . . . . . . . . . . . 8

CHARACTERISTICS OF STUDIES . . . . . . . . . . . . . . . . . . . . . . . . . . . . . . . . . . . . . .

Intravitreal low molecular weight heparin and 5-Fluorouracil for the prevention of proliferative vitreoretinopathy following retinal 
[Intervention Review]

\title{
Intravitreal low molecular weight heparin and 5-Fluorouracil for the prevention of proliferative vitreoretinopathy following retinal reattachment surgery
}

\author{
Venki Sundaram ${ }^{1}$, Allon Barsam ${ }^{2}$, Gianni Virgili ${ }^{3}$ \\ ${ }^{1}$ c/o Cochrane Eyes and Vision Group, ICEH, London School of Hygiene \& Tropical Medicine, London, UK. ${ }^{2}$ Moorfields Eye \\ Hospital NHS Foundation Trust, London, UK. ${ }^{3}$ Department of Specialised Surgical Sciences, University of Florence, Florence, Italy \\ Contact address: Venki Sundaram, c/o Cochrane Eyes and Vision Group, ICEH, London School of Hygiene \& Tropical Medicine, \\ Keppel Street, London, WC1E 7HT, UK. venkisundaram@hotmail.com.
}

Editorial group: Cochrane Eyes and Vision Group.

Publication status and date: New, published in Issue 7, 2010.

Review content assessed as up-to-date: 23 May 2010.

Citation: Sundaram V, Barsam A, Virgili G. Intravitreal low molecular weight heparin and 5-Fluorouracil for the prevention of proliferative vitreoretinopathy following retinal reattachment surgery. Cochrane Database of Systematic Reviews 2010, Issue 7. Art. No.: CD006421. DOI: 10.1002/14651858.CD006421.pub2.

Copyright (C) 2010 The Cochrane Collaboration. Published by John Wiley \& Sons, Ltd.

\section{A B S T R A C T}

Background

Proliferative vitreoretinopathy (PVR) is a significant cause of failure in retinal reattachment surgery. Various pharmacological agents have shown potential benefit in reducing postoperative PVR risk.

Objectives

This review aimed to compare the use of intravitreal low molecular weight heparin (LMWH) alone or with 5-Fluorouracil (5-FU) versus placebo, as an adjunct in the prevention of PVR following retinal reattachment surgery.

Search methods

We searched the Cochrane Central Register of Controlled Trials (CENTRAL) (which contains the Cochrane Eyes and Vision Group Trials Register) (The Cochrane Library 2010, Issue 5), MEDLINE (January 1950 to May 2010), EMBASE (January 1980 to May 2010), the metaRegister of Controlled Trials ( $m$ RCT) (www.controlled-trials.com) and ClinicalTrials.gov (http://clinicaltrials.gov). There were no language or date restrictions in the search for trials. The electronic databases were last searched on 24 May 2010.

\section{Selection criteria}

We only included randomised controlled trials (RCTs) that compared intravitreal LMWH alone or with 5-FU, versus placebo for the prevention of postoperative PVR in patients undergoing primary vitrectomy for rhegmatogenous retinal detachment repair.

\section{Data collection and analysis}

Two review authors independently assessed trial quality and extracted data. The review authors contacted study authors for additional information.

Intravitreal low molecular weight heparin and 5-Fluorouracil for the prevention of proliferative vitreoretinopathy following retinal reattachment surgery (Review)

Copyright $\odot 2010$ The Cochrane Collaboration. Published by John Wiley \& Sons, Ltd. 


\section{Main results}

We included two RCTs (with a total of 789 participants) comparing LMWH with 5-FU infusion and placebo. However, we did not perform a meta-analysis because of significant heterogeneity between these studies. One study found a significant beneficial effect of LMWH with 5-FU in reducing postoperative PVR compared to placebo (RR: $0.48,95 \%$ confidence interval: 0.25 to 0.92 ), in 174 patients who were viewed at high-risk of developing postoperative PVR. The other study included 615 unselected cases of rhegmatogenous retinal detachment and could not show a difference between LMWH with 5-FU infusion and placebo in reducing PVR rates (RR: $1.45,95 \%$ confidence interval: 0.76 to 2.76 ).

\section{Authors' conclusions}

Results from this review indicate that there is inconsistent evidence from two studies on patients at different risk of PVR on the effect of LMWH and 5-FU used during vitrectomy to prevent PVR. Future research should be conducted on high risk patients only, until a benefit is confirmed at least in this patient subgroup.

\section{PLAIN LANGUAGESUMMARY}

Intravitreal low molecular weight heparin and 5-Fluorouracil for the prevention of proliferative vitreoretinopathy following retinal reattachment surgery

Proliferative vitreoretinopathy (PVR) is a retinal scarring process which occurs following retinal detachment. It is a major cause of failure of retinal reattachment surgery and impairment of ultimate visual recovery. Low weight molecular heparin (LMWH) and 5Fluorouracil (5-FU) are agents that can be used during surgery to potentially reduce the amount of PVR following surgery.

The two studies included in this review looked at using LMWH with 5-FU during retinal detachment repair to see if there was an effect of reducing PVR levels after surgery. One study focused on patients who are considered at high-risk of developing PVR after surgery because of pre-existing ocular features, and found beneficial effects of this treatment in this group. The other study looked at a wider group of patients and did not find a benefit in using this combination treatment, and in certain patients the treatment was associated with poorer vision. Due to the inconsistency of the evidence, until further data are available, future research on the use of LMWH with 5-FU should be conducted only in retinal detachment patients who are likely to develop considerable retinal scarring after surgery.

\section{B A C K G R O U N D}

\section{Description of the condition}

Proliferative vitreoretinopathy (PVR) is defined as the growth and contraction of cellular membranes within the vitreous cavity and on both sides of the retinal surfaces. It is an anomalous scarring process in retinal detachments (Rachal 1979; SSG 1992). The condition is the result of proliferation of glial and retinal pigment epithelial cells, both of which normally act as supporting cells for the retina. The retinal epithelial cells change their function to become fibroblast-like cells, normally involved in wound healing and scarring, with contractile properties. The resultant tissue fibrosis and contracture distorts the inner retina resulting in further redetachment. A retinal detachment can be defined as a separation of the neurosensory retina from the underlying retinal pigment epithelium.

Retinal reattachment is achieved with one operation in $70.7 \%$ of cases, and after one or more operations in $97.5 \%$ of cases (Heimann 2006). Proliferative vitreoretinopathy is the most common cause of failed surgery for rhegmatogenous retinal detachment (Rachal 1979; SSG 1992). Rhegmatogenous retinal detachment can be defined as a retinal detachment occurring due to a retinal break or tear that allows the liquid vitreous to pass through the break and detach the retina. This is the most common type of detachment.

\section{Description of the intervention}

A high success rate in primary retinal detachment surgery remains the basis for the prevention of PVR. In cases that develop PVR, 
and in others identified initially as high-risk, the use of adjunctive medical agents is potentially of value in increasing surgical success rates. There are a number of studies showing a potential benefit from a variety of pharmacological interventions, including retinoic acid (Araiz 1993; Campochiaro 1991; Fekrat 1995; Verstraeten 1992), dexamethasone (Hui 1993; Tano 1980; Tano 1981), colchicines (Kirmani 1983; Lemor 1986), paclitaxel (taxol) (Daniels 1990; van Bockxmeer 1985), daunorubicin (Wiedemann 1987; Wiedemann 1991), and 5-Fluorouracil (5-FU) with heparin (Asaria 2001; Kumar 2003).

\section{How the intervention might work}

Low molecular weight heparin (LMWH) has been shown to reduce postoperative fibrin after vitrectomy (Iverson 1991). Heparin binds to fibronectin and to a wide range of growth factors, including acidic and basic fibroblast growth factors and plateletderived growth factors (Blumenkranz 1992). 5-FU inhibits DNA synthesis, inhibits fibroblast proliferation and has been effective in reducing rates of PVR in animal models (Blumenkranz 1984). 5FU and LMWH have actions at different stages of the PVR process, and using these agents in conjunction may produce a synergistic effect.

\section{Why it is important to do this review}

Neither intravitreal LMWH nor 5-FU are in routine clinical use in retinal detachment procedures, and a systematic review may help to ascertain whether routine clinical use of such interventions are beneficial.

\section{O B J E C T IVES}

To compare intravitreal LMWH alone or with 5-FU to placebo as an adjunct in the prevention of PVR following retinal reattachment surgery.

The null hypothesis is that there is no difference between intravitreal LMWH or 5-FU versus placebo as an adjunct for the prevention of PVR following retinal reattachment surgery.

\section{METHODS}

\section{Criteria for considering studies for this review}

\author{
Types of studies
}

We included randomised controlled trials (RCTs) only.

\section{Types of participants}

We included people who were aged 16 years or older and were undergoing primary vitrectomy surgery for rhegmatogenous retinal detachments. We excluded participants who had posterior penetrating trauma, proliferative diabetic retinopathy, corneal opacity sufficient to impair surgical view, premenopausal status (potential teratogenic risk) or previous vitrectomy (Asaria 2001).

\section{Types of interventions}

We considered the following interventions:

1. Intravitreal LMWH (added to vitrectomy infusion fluid).

2. Adjuvant intravitreal LMWH and 5-FU (added to vitrectomy infusion fluid).

3. Placebo (control group) - normal vitrectomy infusion fluid (balanced salt solution).

\section{Types of outcome measures}

\section{Primary outcomes}

The development of postoperative PVR. This was determined at follow-up visits with complete retinal examination within six months postoperatively. The presence or absence of PVR and the reattachment status of the retina were recorded.

Definitions and grading of PVR may vary in the included trials. We recorded the variations in the definitions and noted whether the outcome was measured using a validated technique in the 'Characteristics of included studies' table.

The gold standard for defining and grading PVR is the new adaptation of the Retinal Society Classification described by the Silicone Study Group (Lean 1989). The 1983 Retina Society classification was modified in 1989 by the Silicone Study Group, whose classification differentiates between posterior and anterior forms of PVR and recognises three patterns of proliferation: diffuse, focal and subretinal.

\section{Secondary outcomes}

Reoperation rate and change in visual acuity within six months postoperatively.

\section{Adverse effects (severe, minor)}

Intraoperative ocular haemorrhage, postoperative ocular haemorrhage and retinal redetachment rate. 


\section{Economic data}

The cost of combined LMWH and 5-FU is $\$ 6.00$ (Asaria 2001).

\section{Search methods for identification of studies}

\section{Electronic searches}

We searched the Cochrane Central Register of Controlled Trials (CENTRAL) (which contains the Cochrane Eyes and Vision Group Trials Register) (The Cochrane Library 2010, Issue 5), MEDLINE (January 1950 to May 2010), EMBASE (January 1980 to May 2010), the metaRegister of Controlled Trials ( $m$ RCT) (www.controlled-trials.com) and ClinicalTrials.gov ( http://clinicaltrials.gov). There were no language or date restrictions in the search for trials. The electronic databases were last searched on 24 May 2010.

See: Appendices for details of search strategies for CENTRAL (Appendix 1), MEDLINE (Appendix 2), EMBASE (Appendix 3), $m$ RCT (Appendix 4) and ClinicalTrials.gov (Appendix 5 ).

\section{Searching other resources}

The lead author searched the reference lists of the studies included in the review for information about further trials. We did not handsearch journals or conference proceedings specifically for the review.

\section{Data collection and analysis}

\section{Selection of studies}

Two authors, working independently, assessed the titles and abstracts resulting from the searches. The full copy of all possibly or definitely relevant studies were obtained for further assessment. Both authors assessed these full copies to see if they did indeed meet the inclusion criteria. The lead author contacted study authors for clarification of any details necessary in order to make a complete assessment of the relevance of a study.

\section{Data extraction and management}

We extracted data from each study, ensuring that the patients met the criteria described above under participants, and looked at the outcome measures described above. We looked at dichotomous data for the primary outcomes and at continuous data for the secondary outcomes listed above. The unit of analysis was an individual person.
Data were entered into RevMan 5 by two authors working independently and checked in RevMan 5. We approached the trial authors for information on missing data or where data were difficult to determine from the full copy of the paper.

We extracted the following study characteristics from each study included:

1. Methods: method of allocation, masking (participant, provider, outcome), exclusions after randomisation, losses to follow-up and compliance, unusual study design.

2. Participants: country where participants enrolled, number randomised, age, sex, main inclusion and exclusion criteria.

3. Interventions: treatment, comparison intervention (control), duration of intervention.

4. Outcomes: relevant outcomes on which data were collected in the trial and length of follow-up.

5. Notes: additional details relevant to that particular trial (e.g. funding sources).

\section{Assessment of risk of bias in included studies}

We assessed all full copies for inclusion in the review for methodological quality according to Chapter 8 of the Cochrane Handbook for Systematic Reviews of Interventions 5.0.1 (Higgins 2009). We considered five parameters of quality:

1. Randomisation sequence generation

2. Allocation concealment

3. Masking of surgeon and patients

4. Incomplete outcome data

5. Selective reporting

We assessed each parameter of trial quality and graded it as yes (low risk of bias), no (high risk of bias) or unclear.

\section{Measures of treatment effect}

For dichotomous outcomes we calculated a summary relative risk. We calculated a mean difference for continuous outcomes. We will calculate a standardized mean difference if different scales are used to measure continuous outcomes in studies found when updating this review (Deeks 2009).

\section{Unit of analysis issues}

We did not expect such an issue to be found because these intervention are generally unilateral.

\section{Dealing with missing data}

When there were missing data in a study, unless causes of missingness could not be associated to treatment allocation such as death or patient refused surgery, we used Stata software 11.0 metamiss macro (White 2008) to explore the impact of missing data assuming fixed and opposite informative missing odds ratio (IMOR) 2 or $1 / 2$. 


\section{Assessment of heterogeneity}

The inconsistency of effect estimates across studies was assessed using the $\mathrm{I}^{2}$ statistic and the $\mathrm{Chi}^{2}$ test for heterogeneity. If the $\mathrm{I}^{2}$ statistic was greater than $50 \%$ we considered that to be substantial heterogeneity.

\section{Assessment of reporting biases}

If a sufficient number of studies is found (10 or more) in the updates of this review, we will examine the symmetry of the funnel plot to explore small study and publication bias.

\section{Data synthesis}

For future updates to this review, data analysis will be performed according to the guidelines in Chapter 9 of the Cochrane Handbook for Systematic Reviews of Interventions (Deeks 2009).

If the $\mathrm{I}^{2}$ statistic is greater than $50 \%$ and if there is significant clinical heterogeneity we will not conduct a meta-analysis. Instead we will present a tabulated or narrative summary, or both. If the I ${ }^{2}$ statistic is less than $50 \%$, there is no significant clinical heterogeneity and there is no funnel plot asymmetry, we will combine the effect estimates in a meta-analysis using a random-effects model. We will use a fixed-effect model if there is no statistical or clinical heterogeneity and if the number of trials is fewer than three. This is to avoid reporting less robust effect estimates that may result from random-effects models in situations with very few trials.

\section{Subgroup analysis and investigation of heterogeneity}

For future updates of this review, we will conduct subgroup analyses to investigate for heterogeneity if more studies are found and meta-analysis is possible. The subgroups will be based on: high versus low risk of PVR among controls (greater than 10\%), attached versus detached macula, methods and timing used to deliver 5-FU.

\section{Sensitivity analysis}

For future updates to this review, we will conduct sensitivity analyses to evaluate the impact of variations in definitions of outcomes used in different included trials. We will exclude studies graded as 'no' (high risk of bias) and 'unclear' in assessment of methodological quality. We will examine the impact of excluding studies of lower methodological quality, unpublished data, and industryfunded studies. We will examine whether the summary effect estimate is influenced by any assumptions that have been made during the review.

\section{RE S U L T S}

\section{Description of studies}

See: Characteristics of included studies; Characteristics of excluded studies.

\section{Results of the search}

The electronic searches revealed 309 articles, of which, we identified two RCTs that met our inclusion criteria and were included in the review (Asaria 2001; Wickham 2007). We rejected two papers after obtaining the full text copies (Scheer 2005, Wang 2006). The other 305 articles were either not RCTs or did not specifically concern patients undergoing primary vitrectomy for retinal detachment, and were rejected by viewing their abstract alone.

\section{Included studies}

Two trials (Asaria 2001; Wickham 2007) were included in the review and details are given below. See the 'Characteristics of included studies' table for more details.

\section{Types of participants}

Asaria 2001 recruited 174 patients undergoing primary vitrectomy for rhegmatogenous retinal detachments. All patients were more than 16 years of age and were deemed at high-risk of developing PVR. A regression formula derived from previous studies performed in the groups' department was used to identify patients at high-risk of developing PVR. Risk factors for developing PVR in descending importance were aphakia, preoperative PVR, size of detachment, anterior uveitis, previous cryotherapy and vitreous haemorrhage. Exclusion criteria were posterior penetrating trauma, proliferative diabetic retinopathy, corneal opacity sufficient to impair surgical view, premenopausal status, previous vitrectomy, inability to complete follow-up program and unwillingness to accept randomisation. Patients were followed up for six months following surgery.

Wickham 2007 recruited 641 patients from two specialised vitreoretinal units with rhegmatogenous retinal detachment, undergoing primary vitrectomy with gas tamponade. All patients were over 16 years of age, and unlike Asaria 2001, also included patients who were not viewed at being at risk of developing postoperative PVR. Additional exclusion criteria to Asaria 2001 included giant retinal tears (defined as peripheral retinal tears greater than three clock hours in circumferential extent), intended silicone oil tamponade and no light perception preoperative vision.

\section{Types of interventions}

In Asaria 2001 and in Wickham 2007 patients in the treatment group received a continuous infusion of 5-FU $(200 \mathrm{ug} / \mathrm{ml})$ and LMWH $(5 \mathrm{IU} / \mathrm{ml})$. Normal saline was used as the infusion in the placebo group. In Wickham 2007, silicone oil use was counted as 
a protocol violation and these patients were included for analysis. The number of protocol violations was similar between the two groups $(\mathrm{N}=15$ in the treatment group and $\mathrm{N}=18$ in the placebo group), so this is unlikely to have caused significant bias.

In Asaria 2001, if the operation lasted for more than one hour the infusion bag was replaced with a new identical infusion, whereas in Wickham 2007, the infusion bag was replaced with Hartmann solution irrespective of the group.

All patients underwent standard three-port pars plana vitrectomy, with retinopexy using endolaser, indirect laser or cryotherapy where appropriate. Internal tamponade was achieved with either perfluoropropane (C3F8) gas or sulphur hexafluoride (SF6) gas. Silicone oil was used when indicated in Asaria 2001.

\section{Types of outcome measures}

In Asaria 2001, the primary outcome measure was postoperative PVR, defined as PVR greater than CP1 according to the new Retinal Society Classification. Secondary outcome measures were reoperation rate, change in visual acuity and complication rates. Treatment success was defined as complete retinal reattachment and no reoperations within six months.

In Wickham 2007, the primary outcome measure was retinal reattachment after primary vitrectomy without reoperation at six months. Secondary outcome measures were occurrence and grade of PVR (grade C and above), best corrected visual acuity, intraocular pressure, corneal clarity and complications.

\section{Excluded studies}

We excluded two studies. One study (Wang 2006) appeared to meet our inclusion criteria from the abstract. The rest of the study was published in Chinese. We contacted Dr. Wang Yong directly who confirmed that the study was not an RCT and so was excluded from the review. The second study, Scheer 2005 was rejected after reviewing the full copy as it was not an RCT.

See the 'Characteristics of excluded studies' table for further details.

\section{Risk of bias in included studies}

See Figure 1.

Figure I. Methodological quality summary: review authors' judgements about each methodological quality item for each included study.

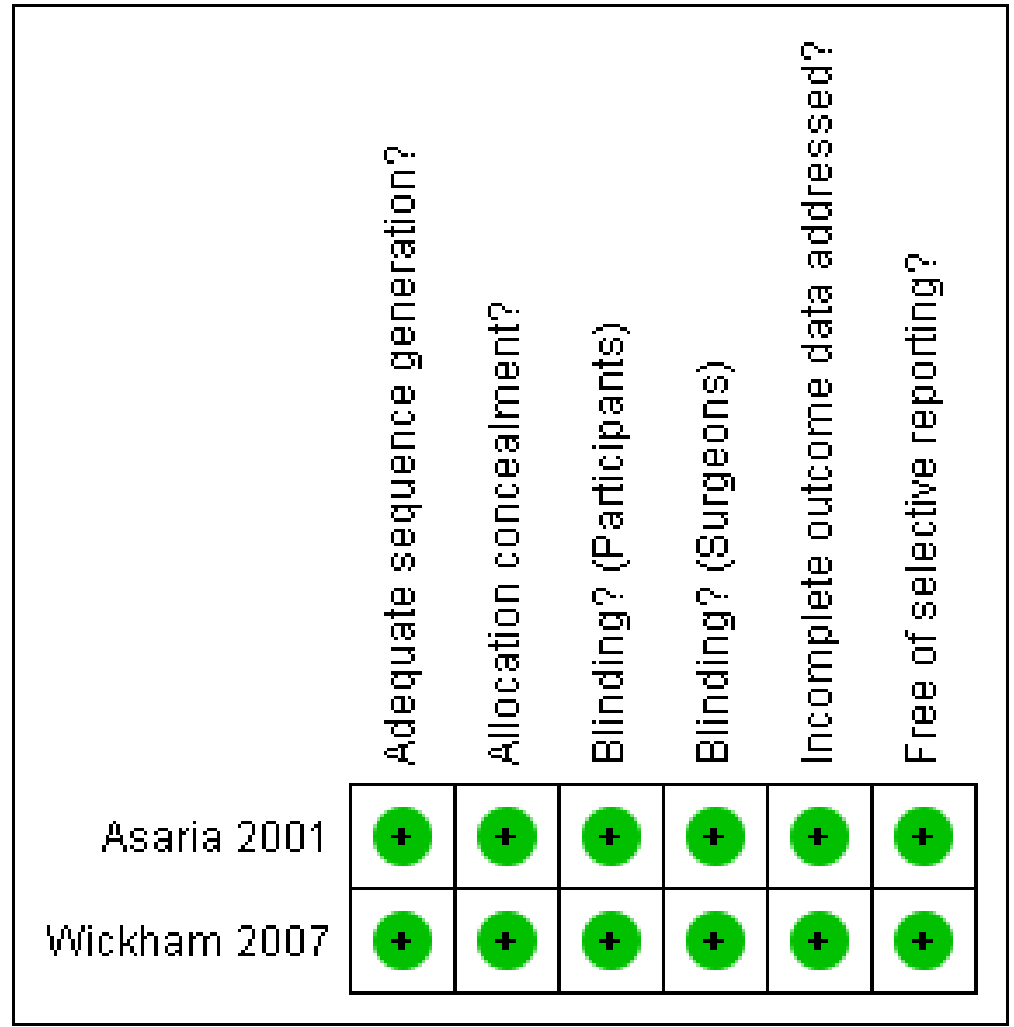

Intravitreal low molecular weight heparin and 5-Fluorouracil for the prevention of proliferative vitreoretinopathy following retinal 


\section{Allocation}

In both studies, randomisation was carried out after patients had been scheduled for surgery and recruited and was performed with the help of a medical statistics support office. A randomisation schedule was used by the pharmacy department who then dispensed coded vials of treatment drugs or placebo.

\section{Blinding}

In both studies, the patients and surgeons were masked (blinded) to the type of infusion fluid being used.

\section{Incomplete outcome data}

In both studies data were analysed according to the group to which patients were assigned (i.e. on an intention-to-treat basis).

In Asaria 2001, data for 5/87 patients in the placebo group and $2 / 87$ patients in the treatment group were missing at three and six month follow up examinations. A simulation on these data as described in the 'Data collection and analysis' section did not substantially change the results.

In Wickham 2007, six month follow up data was incomplete for $15 / 342$ patients in the treatment group and $11 / 299$ patients in the placebo group. We suggest there is no need to carry out simulations on the impact of missing data since the loss was balanced and its causes were also similar and unlikely to be related to treatment outcome (surgery cancelled or patient did not attend or withdrew consent, death).

\section{Selective reporting}

The primary outcome of this review was reported by both studies included in this review using the same definition. Re-operation rates were also reported. Visual acuity change was defined differently in the two studies: Asaria 2001 used a three-level categorisation (worse, stable, better), while Wickham 2007 reported continuous $\log$ MAR visual acuity as median and interquartile range. Thus, there is potential selective reporting, but only regarding this secondary outcome in our review.

We could not investigate publication bias due to the fact that only two studies are included in the review.

\section{Effects of interventions}

\section{5-Fluorouracil and LWMH versus placebo}

Primary outcome: postoperative PVR
We did not perform a meta-analysis since Asaria 2001 and Wickham 2007 yielded estimates of effect in the opposite direction which were heterogeneous $\left(\mathrm{Chi}^{2}\right.$ test for heterogeneity $\mathrm{P}=$ 0.02 and $\mathrm{I}^{2}$ 82\% in Analysis 1.1). Only Asaria 2001 yielded a statistical significant difference favouring LMWH with 5-FU.

\section{Secondary outcomes:}

\section{Reoperation rates}

High heterogeneity between Asaria 2001 and Wickham 2007 was also seen for reoperation rates $\left(\mathrm{Chi}^{2}\right.$ test for heterogeneity $\mathrm{P}=0.08$ and $\mathrm{I}^{2} 67 \%$ in Analysis 1.2), but in this case neither study yielded a statistically significant difference between the two groups.

\section{Change in visual acuity}

The two included studies reported visual acuity differently. We could extract the proportion of people in whom visual acuity had worsened at the last examination from Asaria 2001, and the comparison favoured LMWH with 5-FU (Analysis 1.3).

In Wickham 2007, data were presented as median and interquartile range (IQR). Since there was little evidence of skewness (i.e. the median was roughly centred in the IQR), we used it to approximate means and we used IQR as an estimate of standard deviation (times 1.35 as suggested in Higgins 2009). After such data manipulation we could not show a difference between LMWH with 5-FU and placebo (Analysis 1.4).

\section{Complications}

In Asaria 2001, five patients developed postoperative hyphaema in each group, all of which were mild and settled with conservative treatment. One retinal incarceration and one choroidal haemorrhage occurred in the treatment group.

In Wickham 2007, choroidal haemorrhage occurred in one patient in both the placebo and treatment groups. Two patients had retinal incarceration in the treatment group.

\section{DISCUSSION}

\section{Summary of main results}

Although two trials were included in this review, we did not perform meta-analysis because of statistical heterogeneity between the 
trials for both the primary and the secondary anatomic outcome. This is further substantiated by clinical heterogeneity due to inclusion criteria leading to very different preoperative viewed risk of developing postoperative PVR. Such different inclusion criteria lead to different rates of PVR in the control group of each study (26\% for Asaria 2001 and 5\% for Wickham 2007). The fact that only Asaria 2001 found LMWH with 5-FU beneficial to prevent postoperative PVR could be ascribed to an interaction of treatment with baseline risk, i.e. the control event rate. The rationale for this difference would be that LMWH with 5-FU infusion would only be effective in preventing postoperative PVR in patients undergoing primary vitrectomy for rhegmatogenous retinal detachment who were viewed at high-risk of developing postoperative PVR, whereas in cases of rhegmatogenous retinal detachment at low risk of PVR development its use might be associated with a worse visual outcome in macular sparing detachments as there are concerns about the use of a cytotoxic agent in a continuous infusion such as 5-FU.

However, the hypothesis of an interaction between baseline risk and treatment effect cannot be tested formally in subgroup analysis in our review with only two included studies, so this explanation remains presumptive.

\section{Overall completeness and applicability of evidence}

The heterogeneous results of the two studies regarding the direction of the effect for the primary outcome may suggest that heterogeneity is to be expected in studies on the use of LMWH and 5FU to prevent PVR during vitrectomy. This is in agreement with the fact that this is a complex surgical procedure which can be applied to very different patients. Thus, the evidence collected in this review is largely incomplete and insufficient to guide clinical practice.

\section{Quality of the evidence}

Overall, the studies were good quality, but the inconsistency of their results makes any conclusion difficult to be drawn.

\section{AUTHORS' CONCLUSIONS}

\section{Implications for practice}

There is currently inconsistent evidence from randomised controlled trials on the efficacy of LMWH with 5-FU infusion to prevent PVR after vitrectomy for retinal detachment.

\section{Implications for research}

Future research on LMHW and 5-FU during vitrectomy should be conducted on patients at high risk of PVR, both because there are ethical and theoretical reasons favouring this choice and to enhance study power. Studies on low risk patients should be a later step if treatment is found beneficial in studies on high risk patients.

Furthermore, a $2 \times 2$ block design may be used to investigate the separate effect of 5-FU or LMWH as well as their interaction. In addition, trials looking at the use of a LMWH combined with an intravitreal 5-FU injection at the end of a vitrectomy procedure, would be helpful in identifying routes and doses of administration of therapies that help prevent postoperative PVR in high-risk cases, and are also universally considered as safe approaches.

\section{ACKNOW LEDGEMENTS}

The Cochrane Eyes and Vision Group created and executed the search strategies. We thank James Bainbridge, Catey Bunce and Ann Ervin for peer review comments. Anupa Shah, Managing Editor and Iris Gordon for providing CEVG resources. In addition, we thank Taixiang Wu for assistance with Chinese language articles.

\section{REFERE N C ES}

\section{References to studies included in this review}

Asaria 2001 \{published data only\} Asaria RH, Kon CH, Bunce C, Charteris DG, Wong D, Khaw PT, et al.Adjuvant 5-fluorouracil and heparin prevents proliferative vitreoretinopathy : results from a randomized, double-blind, controlled clinical trial. Ophthalmology 2001; 108(7):1179-83.

Wickham 2007 \{published data only\} Wickham L, Bunce C, Wong D, McGurn D, Charteris DG. Randomized controlled trial of combined 5-fluorouracil and low-molecular-weight heparin in the management of unselected rhegmatogenous retinal detachments undergoing primary vitrectomy. Ophthalmology 2007;114(4):698-704.

\section{References to studies excluded from this review}

Scheer 2005 \{published data only\}

Scheer S, Morel C, Poisson F, Bonnel S, Touzeau O, Sahel JA, et al.Prevention of proliferative vitreoretinopathy using 5-FU heparin: clinical tolerance and efficacy. Journal Francais d' Opthalmologie 2005;28(7):701-6. 
Wang 2006 \{published data only\}

Wang Y, Wang LL, Zhu ZQ, Liu B, Pan AZ, Huang L. Electroretinogram of 5 -fluorouracil and LMWH prevention of proliferative vitreoretinopathy. International Journal of Ophthalmology 2006;6(3):651-3.

\section{Additional references}

\section{Araiz 1993}

Araiz JJ, Refojo MF, Arroyo MH, Leong FL, Albert DM, Tolentino FI. Antiproliferative effect of retinoic acid in intravitreous silicone oil in an animal model of proliferative vitreoretinopathy. Investigative Ophthalmology \& Visual Science 1993;34(3):522-30.

\section{Blumenkranz 1984}

Blumenkranz M, Hernandez E, Ophir A, Norton EW. 5-Fluorouracil: new applications in complicated retinal detachment for an established metabolite. Ophthalmology 1984;91(2):122-30.

\section{Blumenkranz 1992}

Blumenkranz MS, Hartzer MK, Iverson D. An overview of potential applications of heparin in vitreoretinal surgery. Retina 1992;12(Suppl 3):S71-4.

\section{Campochiaro 1991}

Campochiaro PA, Hackett SF, Conway BP. Retinoic acid promotes density-dependent growth arrest in human retinal pigment epithelial cells. Investigative Ophthalmology \& Visual Science 1991;32(1):65-72.

\section{Daniels 1990}

Daniels SA, Coonley KG, Yoshizumi MO. Taxol treatment of experimental proliferative vitreoretinopathy. Graefes Archive for Clinical and Experimental Ophthalmology 1990; 228(6):513-6.

\section{Deeks 2009}

Deeks JJ, Higgins JPT, Altman DG (editors). Chapter 9: Analysing data and undertaking meta-analyses. In: Higgins JPT, Green S (editors). Cochrane Handbook for Systematic Reviews of Interventions Version 5.0.2 [updated September 2009]. The Cochrane Collaboration, 2009. Available from www.cochrane-handbook.org.

Fekrat 1995

Fekrat S, de Juan E Jr, Campochiaro PA. The effect of oral 13-cis-retinoic acid on retinal redetachment after surgical repair in eyes with proliferative vitreoretinopathy. Ophthalmology 1995;102(3):412-8.

Glanville 2006

Glanville JM, Lefebvre C, Miles JN, Camosso-Stefinovic J. How to identify randomized controlled trials in MEDLINE: ten years on. Journal of the Medical Library Association 2006; 94(2):130-6.

\section{Heimann 2006}

Heimann H, Zou X, Jandeck C, Kellner U, Bechrakis NE, Kreusel KM, et al.Primary vitrectomy for rhegmatogenous retinal detachment: an analysis of 512 cases. Graefes Archive for Clinical and Experimental Ophthalmology 2006;244(1): 69-78.

\section{Higgins 2009}

Higgins JPT, Altman DG (editors). Chapter 8: Assessing risk of bias in included studies. In: Higgins JPT, Green $S$ (editors). Cochrane Handbook for Systematic Reviews of Interventions Version 5.0.2 [updated September 2009]. The Cochrane Collaboration, 2009. Available from www.cochrane-handbook.org.

\section{Hui 1993}

Hui YN, Liang HC, Cai YS, Kirchhof B, Heimann K. Corticosteroids and daunomycin in the prevention of experimental proliferative vitreoretinopathy induced by macrophages. Graefes Archive for Clinical and Experimental Ophthalmology 1993;231(2):109-14.

\section{Iverson 1991}

Iverson DA, Katsura H, Hartzer MK, Blumenkranz MS. Inhibition of intraocular fibrin formation following infusion of low-molecular-weight heparin during vitrectomy. Archives of Ophthalmology 1991;109(3):405-9.

\section{Kirmani 1983}

Kirmani M, Santana M, Sorgente N, Wiedemann P, Ryan SJ. Antiproliferative drugs in the treatment of experimental proliferative vitreoretinopathy. Retina 1983;3(4):269-72.

\section{Kumar 2003}

Kumar A, Nainiwal S, Sreenivas B. Intravitreal low molecular weight heparin in PVR surgery. Indian Journal of Ophthalmology 2003;51(1):67-70.

\section{Lean 1989}

Lean JS, Stern WH, Irvine AR, Azen SP. Classification of proliferative vitreoretinopathy used in the silicone study. The Silicone Study Group. Ophthalmology 1989;96(6): $765-71$.

Lemor 1986

Lemor M, Yeo JH, Glaser BM. Oral colchicine for the treatment of experimental traction retinal detachment. Archives of Ophthalmology 1986;104(8):1226-9.

\section{Rachal 1979}

Rachal WF, Burton TC. Changing concepts of failures after retinal detachment surgery. Archives of Ophthalmology 1979; 97(3):480-3.

SSG 1992

Silicone Study Group. Vitrectomy with silicone oil or sulfur hexafluoride gas in eyes with severe proliferative vitreoretinopathy: results of a randomized clinical trial. Silicone Study Report 1. Archives of Ophthalmology 1992; 110(6):770-9.

\section{Tano 1980}

Tano Y, Sugita G, Abrams G, Machemer R. Inhibition of intraocular proliferations with intravitreal corticosteroids. American Journal of Ophthalmology 1980;89(1):131-6.

Tano 1981

Tano Y, Chandler DB, McCuen BW, Machemer R. Glucocorticosteroid inhibition of intraocular proliferation after injury. American Journal of Ophthalmology 1981;91(2): 184-9. 
van Bockxmeer 1985

van Bockxmeer FM, Martin CE, Thompson DE, Constable IJ. Taxol for the treatment of proliferative vitreoretinopathy. Investigative Ophthalmology \& Visual Science 1985;26(8): $1140-7$.

\section{Verstraeten 1992}

Verstraeten T, Hartzer M, Wilcox DK, Cheng M. Effects of vitamin A on retinal pigment epithelial cells in vitro. Investigative Ophthalmology \& Visual Science 1992;33(10): $2830-8$.

\section{White 2008}

White IR, Higgins JP, Wood AM. Allowing for uncertainty due to missing data in meta-analysis--part 1: two-stage methods. Statistics in Medicine 2008;27(5):711-27.

\section{Wiedemann 1987}

Wiedemann P, Lemmen K, Schmiedl R, Heimann K. Intraocular daunorubicin for the treatment and prophylaxis of traumatic proliferative vitreoretinopathy. American Journal of Ophthalmology 1987;104(1):10-4.

\section{Wiedemann 1991}

Wiedemann P, Leinung C, Hilgers RD, Heimann K. Daunomycin and silicone oil for the treatment of proliferative vitreoretinopathy. Graefes Archive for Clinical and Experimental Ophthalmology 1991;229(2):150-2.

* Indicates the major publication for the study 


\section{CHARACTERISTICS OF STUDIES}

\section{Characteristics of included studies [ordered by study ID]}

\section{Asaria 2001}

\begin{tabular}{l|l}
\hline Methods & Double masked, prospective, randomised, placebo-controlled clinical trial \\
\hline Participants & $\begin{array}{l}174 \text { participants with rhegmatogenous retinal detachment who were also viewed at high- } \\
\text { risk of developing postoperative PVR, undergoing primary vitrectomy }\end{array}$ \\
\hline Interventions & $\begin{array}{l}\text { Treatment group received a continuous intraocular LMWH and 5-FU infusion. Placebo } \\
\text { group received normal saline infusion }\end{array}$ \\
\hline Outcomes & Treatment group had significantly lower postoperative PVR rates \\
\hline Notes & \\
\hline
\end{tabular}

\section{Risk of bias}

\begin{tabular}{|c|c|c|}
\hline Item & Authors' judgement & Description \\
\hline Adequate sequence generation? & Yes & $\begin{array}{l}\text { Randomisation was carried out after the pa- } \\
\text { tient had been scheduled for surgery and } \\
\text { recruited. Randomisation was performed } \\
\text { with the help of the medical statistics sup- } \\
\text { port office, and a randomisation sched- } \\
\text { ule was sent to the pharmacy department, } \\
\text { which dispensed coded vials of treatment } \\
\text { drugs or placebo }\end{array}$ \\
\hline Allocation concealment? & Yes & $\begin{array}{l}\text { Coded vials of treatment or placebo were } \\
\text { added to infusion bag just prior to surgery }\end{array}$ \\
\hline $\begin{array}{l}\text { Blinding? } \\
\text { Participants }\end{array}$ & Yes & $\begin{array}{l}\text { Participants masked (blinded) throughout } \\
\text { study and treatment allocation only re- } \\
\text { vealed at end of study }\end{array}$ \\
\hline $\begin{array}{l}\text { Blinding? } \\
\text { Surgeons }\end{array}$ & Yes & $\begin{array}{l}\text { Surgeons masked throughout study and } \\
\text { treatment allocation only revealed at end of } \\
\text { study }\end{array}$ \\
\hline $\begin{array}{l}\text { Incomplete outcome data addressed? } \\
\text { All outcomes }\end{array}$ & Yes & $\begin{array}{l}\text { Follow-up good and similar between both } \\
\text { groups. } 94.3 \% \text { of participants in the } \\
\text { placebo group and } 97.7 \% \text { of participants } \\
\text { in the treatment group completed the six } \\
\text { month follow-up visit }\end{array}$ \\
\hline
\end{tabular}


Asaria 2001 (Continued)

Free of selective reporting? $\quad$ Yes

Selective reporting is not an issue for the primary outcome "development of PVR", or the secondary outcome "reoperation rate". It may be an outcome only for the secondary outcome "visual acuity" as this is a more subjective assessment and was defined differently in both included studies

Wickham 2007

\begin{tabular}{ll} 
Methods & Double masked, prospective, randomised, placebo-controlled clinical trial \\
\hline Participants & $\begin{array}{l}641 \text { participants with rhegmatogenous retinal detachments from two specialist vitreo- } \\
\text { retinal units, with all participants undergoing primary vitrectomy }\end{array}$ \\
\hline Interventions & $\begin{array}{l}\text { Treatment group received a continuous intraocular LMWH and 5-FU infusion. Placebo } \\
\text { group received normal saline infusion }\end{array}$
\end{tabular}
Outcomes
No significant difference in PVR rates between the two groups. Macular sparring de- tachments who received the LMWH and 5-FU infusion had a significantly worse visual acuity

Notes

\section{Risk of bias}

\begin{tabular}{|c|c|c|}
\hline Item & Authors' judgement & Description \\
\hline Adequate sequence generation? & Yes & $\begin{array}{l}\text { After recruitment, non-trial personnel ran- } \\
\text { domised participants on the day of surgery } \\
\text { to the treatment or placebo groups using a } \\
\text { computer generated weighted coin method }\end{array}$ \\
\hline Allocation concealment? & Yes & $\begin{array}{l}\text { Randomisation code kept on separate com- } \\
\text { puter from investigators and pre-prepared } \\
\text { coded infusion fluid used }\end{array}$ \\
\hline $\begin{array}{l}\text { Blinding? } \\
\text { Participants }\end{array}$ & Yes & $\begin{array}{l}\text { Participants masked throughout and treat- } \\
\text { ment allocation only revealed at end of } \\
\text { study }\end{array}$ \\
\hline $\begin{array}{l}\text { Blinding? } \\
\text { Surgeons }\end{array}$ & Yes & $\begin{array}{l}\text { Surgeons masked throughout and treat- } \\
\text { ment allocation only revealed at end of } \\
\text { study }\end{array}$ \\
\hline $\begin{array}{l}\text { Incomplete outcome data addressed? } \\
\text { All outcomes }\end{array}$ & Yes & $\begin{array}{l}\text { Follow-up good and similar between both } \\
\text { groups. } 96.3 \% \text { of participants in the }\end{array}$ \\
\hline
\end{tabular}

Intravitreal low molecular weight heparin and 5-Fluorouracil for the prevention of proliferative vitreoretinopathy following retinal 
Wickham 2007 (Continued)

\begin{tabular}{|c|c|c|}
\hline & & $\begin{array}{l}\text { placebo group and } 95.6 \% \text { of participants } \\
\text { in the treatment group completed the six } \\
\text { month follow-up visit. Causes were also } \\
\text { similar in the two groups and also un- } \\
\text { likely to be related to treatment outcome } \\
\text { (surgery cancelled, participant did not at- } \\
\text { tend or withdrew consent, death) }\end{array}$ \\
\hline Free of selective reporting? & Yes & $\begin{array}{l}\text { Selective reporting is not an issue for the } \\
\text { primary outcome "development of PVR", } \\
\text { or the secondary outcome "reoperation } \\
\text { rate". It may be an outcome only for the } \\
\text { secondary outcome "visual acuity" as this is } \\
\text { a more subjective assessment and was de- } \\
\text { fined differently in both included studies }\end{array}$ \\
\hline
\end{tabular}

5-FU: 5-Fluorouracil

LMWH: low molecular weight heparin

PVR: proliferative vitreoretinopathy

Characteristics of excluded studies [ordered by study ID]

Study Reason for exclusion

Scheer 2005 Not a randomised controlled trial.

Wang 2006 Not a randomised controlled trial. 